\title{
Sensitivity Analysis of Packed Bed Phase Change Material Thermal Storage for Domestic Solar Thermal System
}

\author{
Mikelis DZIKEVICS ${ }^{1 *}$, Ivars VEIDENBERGS ${ }^{2}$, Kęstutis VALANČIUS ${ }^{3}$ \\ ${ }^{1,2}$ Institute of Energy Systems and Environment, Azenes iela 12/1, Riga, LV-1048, Latvia \\ ${ }^{3}$ Department of Building Energetics, Faculty of Environmental Engineering, Vilnius Gediminas Technical \\ University, Sauletekio st. 11, Vilnius, LT-10223, Lithuania
}

\begin{abstract}
Increase in solar fraction has been noted as one of the main goals for wider application of domestic solar thermal systems. To increase solar fraction, higher energy density thermal storage availability is a key point. In this paper phase change materials have been analysed as part of a domestic solar thermal system. Sensitivity analysis of annual simulation in TRNSYS with climate data of Riga, Latvia is used. The paper also explores better methods for evaluating phase change material (PCM) performance based on temperature measurements in PCM. The results showed that the melting point of PCM and temperature set point of an auxiliary heater have the highest sensitivity of aspects analysed in the paper. It also reports that the coefficient of variation of energy in PCM correlates well with solar fraction and can be used as a parameter to evaluate PCM's suitability for certain applications.
\end{abstract}

Keywords - Energy accumulation; latent heat; phase change materials.

\begin{tabular}{|lll|}
\hline Nomenclature & & \\
PCM & Phase change material & - \\
ST & Solar thermal & - \\
$T$ & Temperature & ${ }^{\circ} \mathrm{C}$ \\
$I$ & Irradiance & $\mathrm{kJ} / \mathrm{m}^{2}$ \\
$\dot{m}$ & Mass flow rate & $\mathrm{kg} / \mathrm{s}$ \\
$\mathrm{HEX}$ & Heat exchanger & - \\
DHW & Domestic hot water & - \\
$\mathrm{SF}$ & Solar fraction & - \\
$\lambda$ & Thermal conductivity & $\mathrm{W} /(\mathrm{m} \cdot \mathrm{K})$ \\
$\mathrm{C}_{\mathrm{p}}$ & Specific heat capacity & $\mathrm{kJ} /(\mathrm{kg} \cdot \mathrm{K})$ \\
$Q$ & Energy & $\mathrm{kJ}$ \\
$C H$ & Charge & $\%$ \\
$\sigma$ & Standard deviation & - \\
$\gamma$ & Mean value & - \\
\hline
\end{tabular}

* Corresponding author.

E-mail address: mikelis.dzikevics@rtu.lv 


\begin{tabular}{|lll|}
\hline OAT & One-at-a-time method name & - \\
Subscripts & & - \\
$t$ & Storage tank & - \\
Col & Solar collector & - \\
Aux & Auxiliary heat & - \\
Avg & Average & - \\
loss & Heat loss & \\
\hline
\end{tabular}

\section{INTRODUCTION}

In Europe in the residential sector, space heating makes up more than $64 \%$ of final energy consumption. Around $15 \%$ is used for the preparation of hot water [1]. Households made up $27.2 \%$ of the final energy consumption of EU-28 in 2017 [2]. Although solar thermal (ST) energy is suitable for preparation of low-temperature heat which is required by households, only $17.5 \%$ of primary energy was produced from renewable energy sources, and ST energy made up $0.6 \%$ of primary energy sources [3].

Some of the reasons for the low share of ST energy is that technology has seen little development throughout the years and lacks new storage technologies that have reached market maturity. Meanwhile competitive solar technologies such as PV undergo constant efficiency increase which is brought to market. Also, more research has been focused to understand the best methods for integration in district heating [4]. This can also be seen by looking at the limiting factors for installation of ST systems noted in a report from the year 2008. It is said that main technological limitations relate to the lack of space, lack of high-density energy storage and availability of appropriate materials. In the same report, it is said that such high-density storage could assist in solving these issues, but in most ambitious scenarios, such high-density storage would become available by 2020 [5].

A more recent study by [6] concluded that countries like Germany, Austria, Italy and Denmark have the potential to increase ST in the range from $2 \%$ to $12 \%$ of the total heat production while sensitivity analysis showed that the investment cost for small systems have to decrease by $65 \%$ in 2050 compared to today, for ST to be cost-competitive. The solar fraction used in the study for a single house combined ST system is $20 \%$. In the 2008 report, an increase in solar fraction was noted as one of the aspects that have to be improved to achieve higher adaptation of the technology. This leads to question if increased solar fraction by use of high-density storage could increase the potential share in total heat production and increase price competitiveness.

Use of phase change materials (PCMs) for thermal storage of solar energy has been widely studied, however, there is a lack of certainty of their usefulness and efficiency in domestic application. This is due to a large number of possible combinations of PCM materials [7], capsulation materials [8], sizes, shapes, additives and other heat transfer improvement methods [9] and also many possible heat generation and load combinations.

PCMs have been studied for many years, for example, some of the first applications were studied by NASA in the 1970s [10]. Also the use of multiple melting point PCMs together have been studied experimentally and mathematically back in 1989 [11]. Nowadays the scope of most of the studies rarely is at the level of the overall system and few studies analyse the annual performance of the system that considers seasonal changes and load dynamics. One of the papers that analysed annual performance is by Kousksou et al. [12]. This study was a 
follow-up to a similar study by Talmatsky and Kribus [13], which concluded that annual results show that addition of PCM provides no energetic advantage to the end-user. Kousksou et al. [12] using a similar system and mathematical approach, managed to obtain some improvement with a PCM system over a traditional system, with a note that the performance of the domestic hot water (DHW) system is highly sensitive to the design parameters.

Therefore, the object of this study is to understand which parameters have the highest impact on the solar fraction and solar collector efficiency for a single household solar thermal system with an accumulation tank and auxiliary heat source.

Another aim of the paper is to illustrate the methods for describing the utilization of the PCM latent phase. The main aim of the PCM system is to increase system performance, therefore such parameters as solar fractio (SF) and collector efficiency are analysed. A method to separate the PCM performance from the rest of the system would help to find the optimal parameters for the PCM and understand their impact on the overall efficiency more clearly. Some of the approaches in other papers have been based on temperatures [14]-[16], however, these have been applied only for short term experiments and for heat exchanger type of PCM system, which have defined inlet and outlet temperature.

\section{SET-UP OF THE SYSTEM}

The system of the study is assumed to be suitable for a household of 3 persons for hot water preparation. There is a defined hot water draw-off profile as in Fig. 1 based on the European reference tapping cycles [17]. The chosen tapping cycle assumes average water consumption of 50 litres per person, adding to 150 litres per day. Tapping cycle is constant every day of the year. The climate of Riga, Latvia is used. The outputs from climate data are used as inputs for thermal collectors. The outputs are changing ambient temperature and incident, total horizontal and horizontal diffused radiation.

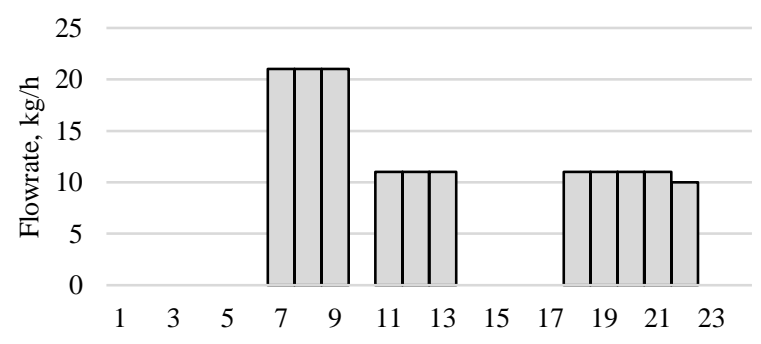

Time, h

Fig. 1. Daily water draw-off profile.

The Cabinet of Ministers of Latvia [18] regulates that the allowed temperature range of hot water in domestic hot water (DHW) systems must be in the range from $55^{\circ} \mathrm{C}$ to $70{ }^{\circ} \mathrm{C}$. Therefore, the heating system in this study is set to provide hot water at $55^{\circ} \mathrm{C}$. To control the temperature delivered to the load, there is a flow diverter used after the cold-water source and a tee-piece mixing element before the load (Fig. 2).

In the mathematical model, a cylindrical tank with a volume of 353 litres is used. The tank design was previously used to analyse the flow rate impact [19]. It has a height of $1.26 \mathrm{~m}$ and 
a height/diameter ratio of 2.2. The tank has a heat loss value $U_{-}$loss of $0.98 \mathrm{~W} /\left(\mathrm{m}^{2} \mathrm{~K}\right)$. Solar collectors have an area of $5 \mathrm{~m}^{2}$ and collector maximum thermal efficiency of 0.8 .

The design of the heating system (Fig. 2) consists of a tank, collector loop, auxiliary heating loop and load side. Simulation is carried out in transient process simulation software TRNSYS version 17 . The tank is filled with water and directly connected to the load, with the inlet at the bottom and outlet at the top of the tank. The solar collector loop consists of a submerged heat exchanger $\left(\mathrm{HEX}_{\mathrm{Col}}\right)$ with a length of $20 \mathrm{~m}$, ID $18 \mathrm{~mm}$ and OD $20 \mathrm{~mm}$ made out of copper with $\lambda$ of $300 \mathrm{~W} /(\mathrm{m} \cdot \mathrm{K})$. Auxiliary $\mathrm{HEX}_{\text {aux }}$ has a length of $10 \mathrm{~m}$, same diameters and materials as $\mathrm{HEX}_{\mathrm{Col}}$. Both loops use a fluid with $\mathrm{C}_{\mathrm{p}}$ of $4.19 \mathrm{~kJ} /(\mathrm{kg} \cdot \mathrm{K})$. The auxiliary heater is turned on based on the temperature of the water at the level of the bottom of HEX aux.

In TRNSYS each component is described by their names as Types and naming these types help other researchers to recreate the model. Each Type is further connected in-between and their parameters can be changed. This model uses Type $1 \mathrm{~b}$ solar collector, Type 840 storage tank developed by [20], Type 6 auxiliary heater, Type 114 pumps and Type $2 \mathrm{~b}$ controllers for solar and auxiliary loops. Type 840 has been validated with its previous name Type 240 [21].

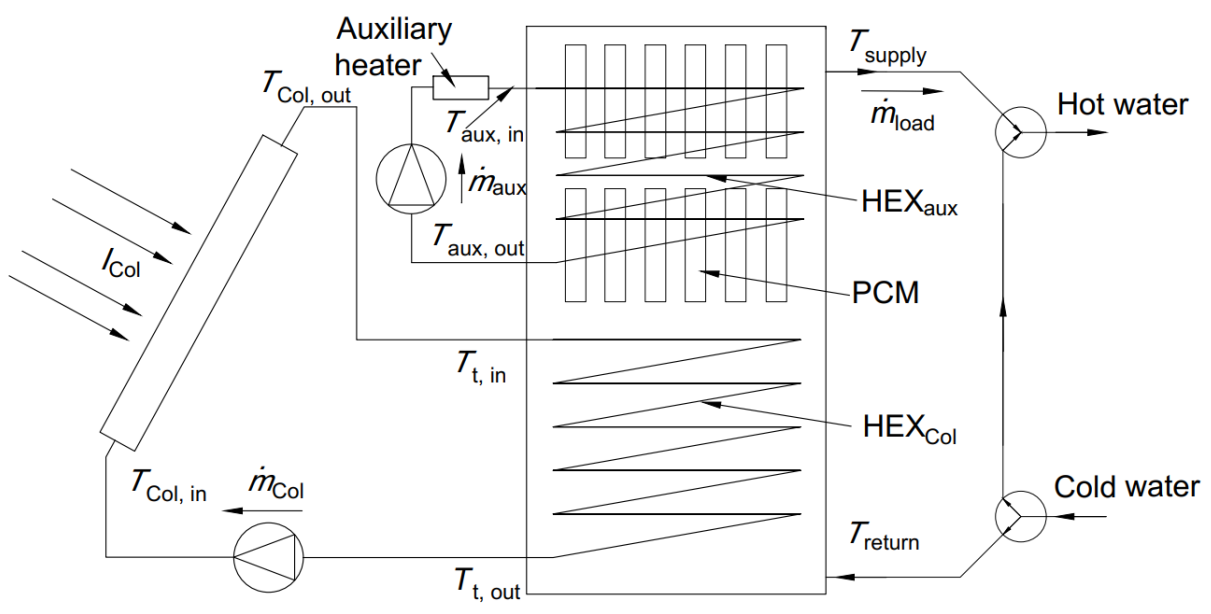

Fig. 2. Solar heating system used for sensitivity analysis with external auxiliary heater.

PCM in the system is placed inside the containers. Containers are free-floating, therefore the arrangment is called a packed bed. In experimental systems some type of shelves would be used to separate different layers of containers and ensure that they stay within the required level of the tank. The packed bed layout is used because it provides a large heat-transfer surface area between PCM within containers and heat transfer fluid.

In the study by [12] and [13] the auxiliary heater is used right after the tank. In the former paper, it is said that the placement of the heater inside the tank can lead to unnecessary heating when there is already enough solar radiation. Therefore, in their studies a heater is placed after the tank. However, in solar thermal systems in northern countries, where there is a long period of low solar radiation, heating water with flow-through heaters is not used since in that case only an electric heater can be used and it would require high power and amperage to heat water to the required temperature on demand.

For PCM to provide the benefit of latent storage, the temperature of water at the level of the container has to reach the melting point of the PCM for long enough that the PCM changes 
phase. Also, the temperature must fluctuate around this melting point temperature, to ensure that PCM not only melts (charges) but also solidifies (discharges). In this study temperature frequency graphs are used which show how often a certain temperature is reached in a given level of the tank. In Fig. 3 and Fig. 4 comparison is carried out between two designs with a tank filled with only water without PCM. Excluding PCM provides more pronounced temperature frequency peaks. In both cases there is a solar heating loop with HEX at the bottom of the tank. In the first design (Fig. 3), the auxiliary flow-through heater is installed outside the tank on the hot water outlet line. In the second case (Fig. 4) design of the system such as in Fig. 2 (excluding PCM) is analysed with submerged auxiliary HEX at the top of the tank. In both cases Type 60 tank is used with volume divided into 15 layers, $1^{\text {st }}$ layer being the very top and $15^{\text {th }}$ layer the very bottom.

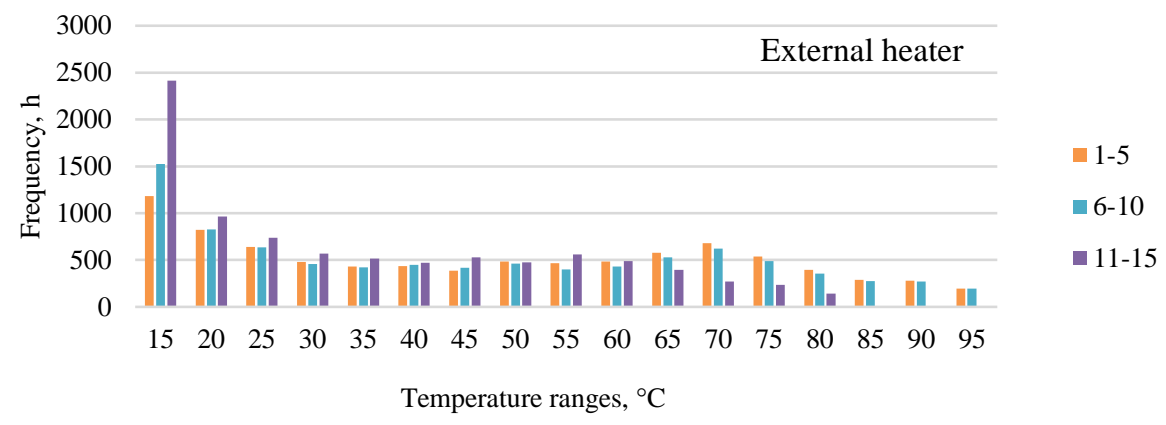

Fig. 3. Hourly frequency of temperature ranges with external flow-through heater after the tank for annual simulation.

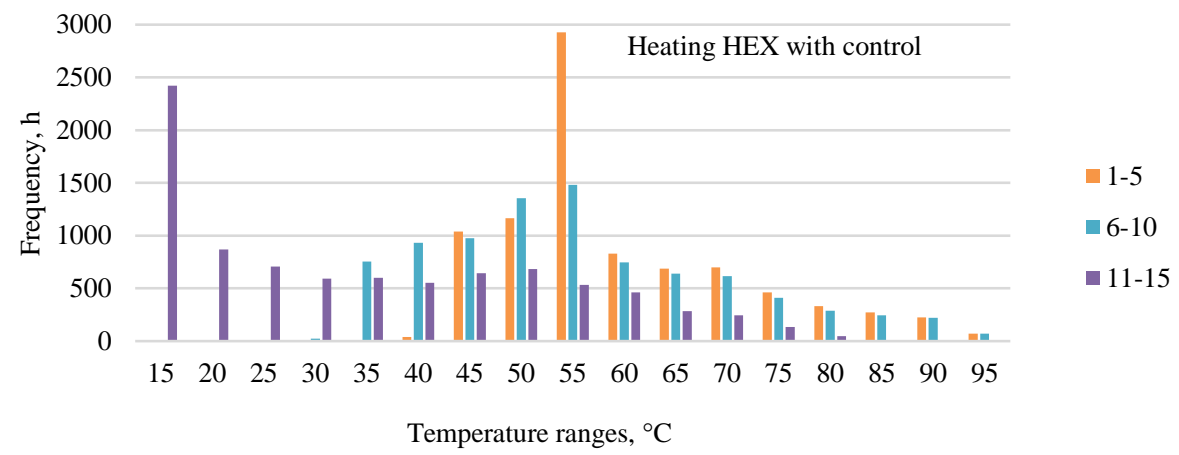

Fig. 4. Hourly frequency of temperature ranges with heating HEX and dead band control for annual simulation.

In Fig. 3 the temperature of $15^{\circ} \mathrm{C}$ has the highest frequency in all levels of the tank and higher temperatures are reached more often during summer months. In comparison, if auxiliary heat is added in the top of the tank (Fig. 4), $55^{\circ} \mathrm{C}$ has the highest frequency in the top portion of the tank. Therefore, the chosen design is with $\mathrm{HEX}_{\text {aux }}$ and an external heat source with constant power of $2 \mathrm{~kW}$, circulation flow rate of $200 \mathrm{~kg} / \mathrm{h}$ and controlled by water temperature sensor at the level of bottom of $\mathrm{HEX}_{\mathrm{aux}}$ with the use of dead bands. The upper dead band is $10{ }^{\circ} \mathrm{C}$ and the lower dead band is $2{ }^{\circ} \mathrm{C}$, which means, that the auxiliary heater is turned on if the temperature falls below $53{ }^{\circ} \mathrm{C}$ and turned off when it heats above $65{ }^{\circ} \mathrm{C}$. 
Salt hydrate PCM with enhanced thermal conductivity (Table 1) is used as a PCM in this study. In TRNSYS the thermophysical properties of PCM are defined in a table. TRNSYS looks up values of enthalpy, density, thermal conductivity and kinematic viscosity depending on the temperature of the PCM from this table. Lateral three are kept constant within this study.

TABLE 1. THERMOPHYSICAL PARAMETERS FOR PCM

\begin{tabular}{lr}
\hline Parameter & Value \\
\hline Specific heat (solid), $\mathrm{kJ} /(\mathrm{kg} \cdot \mathrm{K})$ & 1.87 \\
Specific heat (liquid), $\mathrm{kJ} /(\mathrm{kg} \cdot \mathrm{K})$ & 2.45 \\
Latent heat, $\mathrm{kJ} / \mathrm{kg}$ & 185 \\
Density, $\mathrm{kg} / \mathrm{m}^{3}$ & 1100 \\
Thermal conductivity (solid and liquid), $\mathrm{W} /(\mathrm{m} \cdot \mathrm{K})$ & 4.5 \\
Kinematic viscosity, $(\mathrm{N} \cdot \mathrm{s}) / \mathrm{m}^{2}$ & 10000 \\
\hline
\end{tabular}

\section{Methodology}

For the sensitivity analysis, the one-at-a-time (OAT) method is used. There are 5 aspects and 4 variances for each aspect (Table 2), which totals 20 simulations. Parameters such as SF and collector efficiency are calculated for each simulation. The resulting values are then compared in the Results chapter.

TABLE 2. SUMMARY OF ASPECT VALUES FOR SENSITIVITY ANALYSIS

\begin{tabular}{cccccc}
\hline & $\begin{array}{c}\text { Number of } \\
\text { containers }\end{array}$ & $\begin{array}{c}\text { Melting point, } \\
{ }^{\circ} \mathbf{C}\end{array}$ & $\begin{array}{c}\text { Thermal conductivity, } \\
\mathbf{W} /(\mathbf{m} \cdot \mathbf{K})\end{array}$ & $\begin{array}{c}\text { Latent heat of } \\
\text { fusion, } \mathbf{k J} / \mathbf{k g}\end{array}$ & $\begin{array}{c}\text { Heater } \\
\text { setpoint, }{ }^{\circ} \mathbf{C}\end{array}$ \\
\hline Base & $\mathbf{1 5 0}$ & $\mathbf{5 5 . 0}$ & $\mathbf{4 . 5}$ & $\mathbf{1 8 5 . 0}$ & $\mathbf{5 5 . 0}$ \\
$-5 \%$ & 143 & 52.3 & 4.3 & 175.8 & 52.3 \\
$-10 \%$ & 135 & 49.5 & 4.1 & 166.5 & 49.5 \\
$+5 \%$ & 158 & 57.8 & 4.7 & 194.3 & 57.8 \\
$+10 \%$ & 165 & 60.5 & 5.0 & 203.5 & 60.5 \\
\hline
\end{tabular}

Solar fraction (SF) describes the ratio of the solar yield from total energy input in the system. Daily SF of 1 is achieved when there is enough sun in the given day or there is solar heat stored from previous days which allow the system to run without auxiliary heating. The value of $1^{-6}$ is added so that in case of no solar radiation and auxiliary heating, the calculation would not produce an error in TRNSYS due to division with zero.

$$
S F=\frac{Q_{\mathrm{Col}}}{Q_{\mathrm{Col}}+Q_{\mathrm{Aux}}+1^{-6}}
$$

An indicator $\beta_{54}$ is used to evaluate if the system produces hot water with the required temperature. $\beta_{54}$ shows how often the temperature of the hot water is below $54{ }^{\circ} \mathrm{C}$ with a setpoint of $55^{\circ} \mathrm{C}$. This value is calculated only from the period when there is flow towards the load.

$$
\beta_{54}=\frac{n_{54}}{n_{\mathrm{DHW}}} \cdot 100
$$


For annual simulation, $n_{54}$ is the number of minutes with $T_{\mathrm{DHW}}$ below $54{ }^{\circ} \mathrm{C}$ and $n_{\mathrm{DHW}}$ is number of minutes with $m_{\text {DHW }}$ above 0 in a year.

Solar collector efficiency is calculated with the following equation, where $I_{\mathrm{Col}}$ is tilted radiation on solar collector and $A_{\mathrm{Col}}$ is the area of a collector.

$$
\eta_{\mathrm{Col}}=\frac{Q_{\mathrm{Col}}}{\left(I_{\mathrm{Col}} \cdot A_{\mathrm{Col}}+1^{-6}\right)}
$$

Looking at ways how to describe PCM, additional parameters - charge and discharge counts are used. Charge describes how often PCM is fully charged, which means that PCM has fully changed its phase from solid to liquid and similarly discharge happens when it has fully solidified. However, charge count could be zero and PCM could still fluctuate within the range of 0 to $100 \%$, therefore an average charge is also used:

$$
C H_{\mathrm{Avg}}=\frac{1}{n} \sum_{i=1}^{n} C H_{i}
$$

$\mathrm{CH}_{\text {Avg }}$ of $50 \%$ and an equal and high number of charges and discharges is the optimal utilization of the PCM latent phase. However, the drawback is that all three parameters have to be analysed together, and there is no single value that helps to choose the best solution.

Coefficient of variation $(C V)$ is another option - it looks at the standard deviation $(\sigma)$ of the values in ratio to an average value $(\gamma)$ throughout the year. If the values variate a lot around the average value, then the $C V$ is higher. This could show that variations happen - however, it does not mean that variations happen within latent phase - those could be variations for PCM in a solid or liquid phase, therefore it should be used in combination with $\mathrm{CH}_{\mathrm{Avg}}$.

$$
C V=\frac{\sigma}{\gamma}
$$

In this paper, $C V$ is based on energy change in PCM $\left(C V_{\mathrm{PCM}}\right)$.

\section{Results}

The base scenario is used as a reference case to analyse the change in efficiency parameters. The two main parameters analysed are solar collector efficiency and solar fraction. In Fig. 5 the melting point and heater setpoint show the largest impact on solar collector efficiency. The changes in thermal conductivity, number of containers and latent heat result in relatives changes below $1 \%$. These changes would be smaller than the uncertainty which comes with the simulation approach.

Similarly to solar collector efficiency, the solar fraction shows the same picture with melting point decrease resulting in lower SF and increase has minimal impact. Also, the only other aspect that has any impact is heater setpoint. Here the decrease of $5 \%$ and $10 \%$ results in SF increase by $5 \%$ rel. and $9.6 \%$ rel. respectively, while increase by $5 \%$ and $10 \%$ result in SF decrease by $6.4 \%$ rel. and $9 \%$ rel. respectively. 


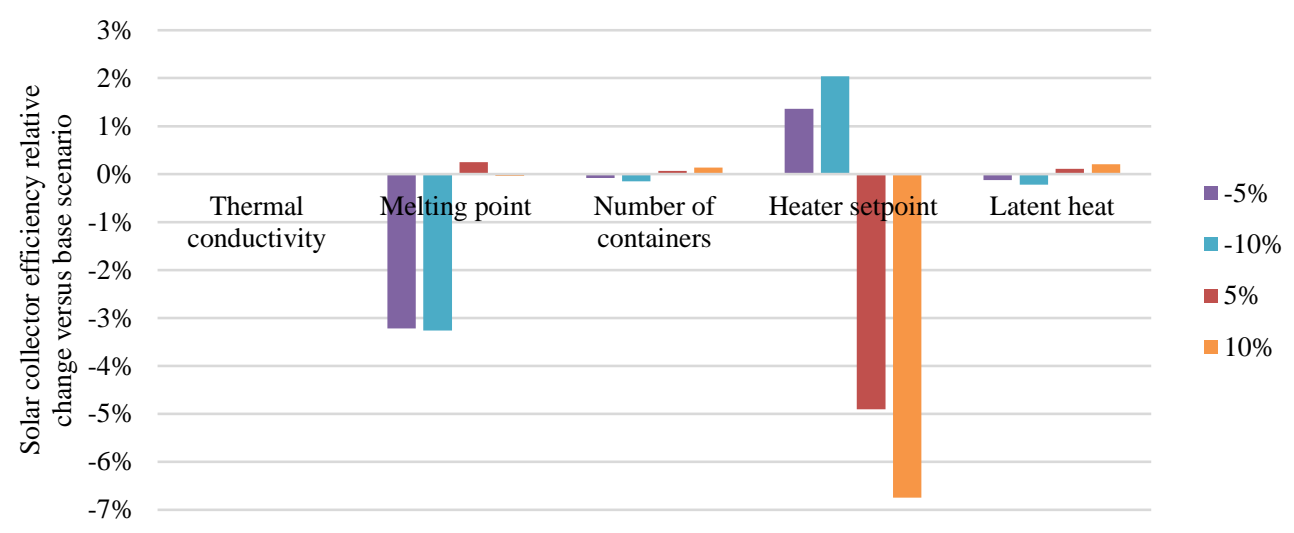

Fig. 5. Solar collector efficiency sensitivity.

\subsection{Melting Point}

Looking closer at the melting point, in Fig. 6 it can be seen that by reducing the melting point, annual energy produced by solar collectors falls by around $60 \mathrm{kWh}$, while the increase in additional required auxiliary heat increases by $73 \mathrm{kWh}$ increasing heat losses by $18 \mathrm{kWh}$.

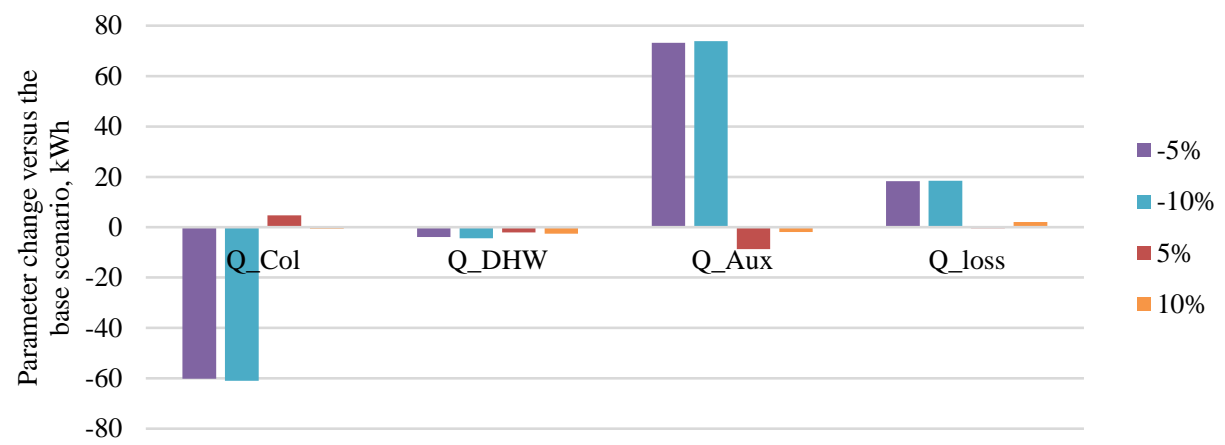

Fig. 6. Melting point change impact on energy.

The impact of changing melting point can be more directly seen looking at the charge count of the PCM. Reduction of the melting point reduces full charge count from 52 in the base case to 10 cases with $-5 \%$ and 1 case with $-10 \%$ with insignificant change in discharge count (Table 3). Lower melting point allows PCM to melt sooner, however, it has a low chance of solidifying or falling below $0 \%$ charge, thus it does not trigger charge count. Increasing the melting point results in up to 79 more discharges. Fig. 7 illustrates that $+10 \%$ case does not reach as high charge values and it discharges sooner compared to the base case. This also shows up in average charge $\left(\mathrm{CH}_{\text {Avg }}\right)$ which is $48 \%$ for the base case and $39 \%$ for increased melting point.

Looking at $C V_{\mathrm{PCM}}$ values; the base case has a $C V$ of 0.45 , for $-10 \% C V$ is 0.09 and for $+10 \% C V$ is 0.58 . In this case, also $C V$ correlates well with SF values with $R^{2} 0.97$. 
Table 3. Charge and Discharge Count For Melting Point Sensitivity AND HEATER SETPOINT

\begin{tabular}{ccccc}
\hline & \multicolumn{2}{c}{ Melting point } & \multicolumn{2}{c}{ Heater setpoint } \\
\hline & $\begin{array}{c}\text { Charge } \\
\text { count }\end{array}$ & $\begin{array}{c}\text { Discharge } \\
\text { count }\end{array}$ & Charge count & $\begin{array}{c}\text { Discharge } \\
\text { count }\end{array}$ \\
\hline Base & $\mathbf{5 2}$ & $\mathbf{1}$ & $\mathbf{5 2}$ & $\mathbf{1}$ \\
$-5 \%$ & 10 & 1 & 51 & 1 \\
$-10 \%$ & 1 & 2 & 47 & 47 \\
$+5 \%$ & 46 & 80 & 2 & 1 \\
$+10 \%$ & 44 & 47 & 1 & 1 \\
\hline
\end{tabular}

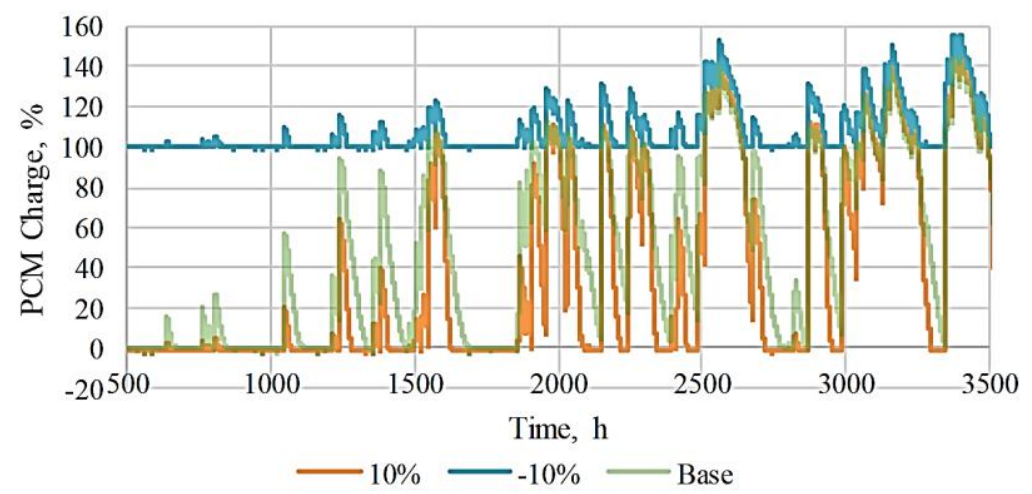

Fig. 7. Minute data for part of the year of PCM charge data for the base case and cases with increased and decreased by $10 \%$ melting temperature of PCM.

In summary, this shows that the slightly higher melting point, compared to the temperature that is set for the domestic hot water, has lesser impact on the solar collector efficiency since PCM still can utilize its latent phase, especially during the summer period, when solar radiation heats the tank more than the auxiliary heater. Meanwhile, the lower melting point can make PCM unsuitable throughout the year without any benefits to traditional sensible heating systems.

\subsection{Heater Setpoint}

Heater setpoint has the highest impact on the overall system performance. In these simulations, the heater is controlled by the temperature in the water at the bottom of the HEX $_{\text {aux. }}$ This is a standard method in heating systems so that the top portion of the tank would prepare enough hot water for periods when more water is needed - mornings and evenings. 


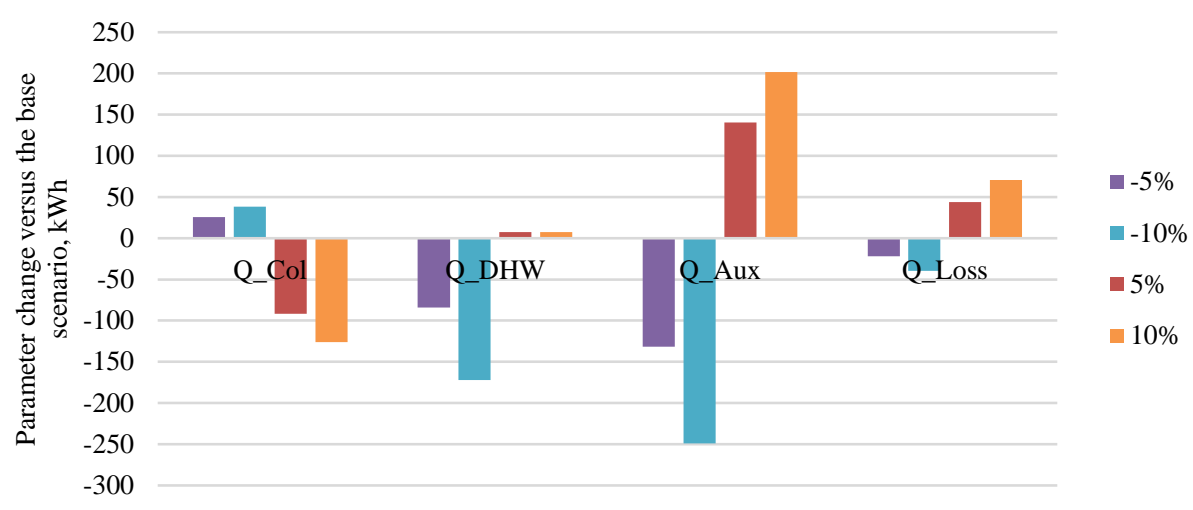

Fig. 8. Heater setpoint change impact on energy

Lower heater setpoint results in $3.1 \%$ to $5.9 \%$ increase in SF while below a $1 \%$ increase in collector efficiency. The reason for the difference in the change can be seen in Fig. 8, where the absolute change in $Q_{\text {Aux }}$ is larger than the change in $Q_{\mathrm{Col}}$. The former directly affects $\mathrm{SF}$, while $\eta_{\mathrm{Col}}$ is not directly affected.

What also can be seen is the reduction in $Q_{\mathrm{DHW}}$ with the reduction of $Q_{\text {Aux }}$. Lower heater setpoint reduces the time when the auxiliary heater is turned on directly affecting how much energy is available for the preparation of hot water. Reducing heater setpoint from $55^{\circ} \mathrm{C}$ to $52.3{ }^{\circ} \mathrm{C}$ or $49.5^{\circ} \mathrm{C}$ increase the period where hot water temperature falls below $54{ }^{\circ} \mathrm{C}$ to larger than $47 \%$ (Table 4). For 4.2 case, the temperature in the range from $49{ }^{\circ} \mathrm{C}$ to $50{ }^{\circ} \mathrm{C}$ is reached around $40 \%$ of the time, while temperature from $54{ }^{\circ} \mathrm{C}$ to $55^{\circ} \mathrm{C}$ additional $40 \%$ and around $10 \%$ above $55{ }^{\circ} \mathrm{C}$ and the rest in-between $50{ }^{\circ} \mathrm{C}$ and $54{ }^{\circ} \mathrm{C}$.

TABLE 4. HEATER SETPOINT PARAMETER SUMMARY

\begin{tabular}{ccccccccc}
\hline Variance & Case & $\begin{array}{c}\text { Setpoint } \\
\text { temperature, } \\
\end{array}$ & \multicolumn{2}{c}{ Temperature, ${ }^{\circ} \mathbf{C}$} & $\boldsymbol{\beta}_{54}$ & $\mathbf{C H}_{\text {Avg }}$ & $\boldsymbol{C V}_{\mathbf{P C M}}$ \\
\hline & Base & 55.0 & 55.1 & 54.5 & 54.9 & $0.0 \%$ & $48 \%$ & 0.45 \\
$-5 \%$ & 5.1 & 52.3 & 55.1 & 51.6 & 53.6 & $47.5 \%$ & - & 0.54 \\
$-10 \%$ & 5.2 & 49.5 & 55.1 & 49.0 & 52.2 & $50.8 \%$ & $47 \%$ & 0.57 \\
$+5 \%$ & 5.3 & 57.8 & 55.1 & 55.0 & 55.0 & $0.0 \%$ & - & 0.09 \\
$+10 \%$ & 5.4 & 60.5 & 55.1 & 55.0 & 55.0 & $0.0 \%$ & $111 \%$ & 0.08 \\
\hline
\end{tabular}

Both cases with reduced setpoint have a similar number of charges, while reduction by $10 \%$ have an additional number of discharges (Table 3 ) because lower heater setpoint allows PCM to cool down below melting point more often. For case 4.2 with $-10 \%$, the $\mathrm{CH}_{\mathrm{Avg}}$ is $47 \%$, indicating that values are distributed evenly, while case 5.4 has $C H_{\text {Avg }}$ of $111 \%$, indicating that reduced setpoint leads to PCM staying in a liquid phase. 


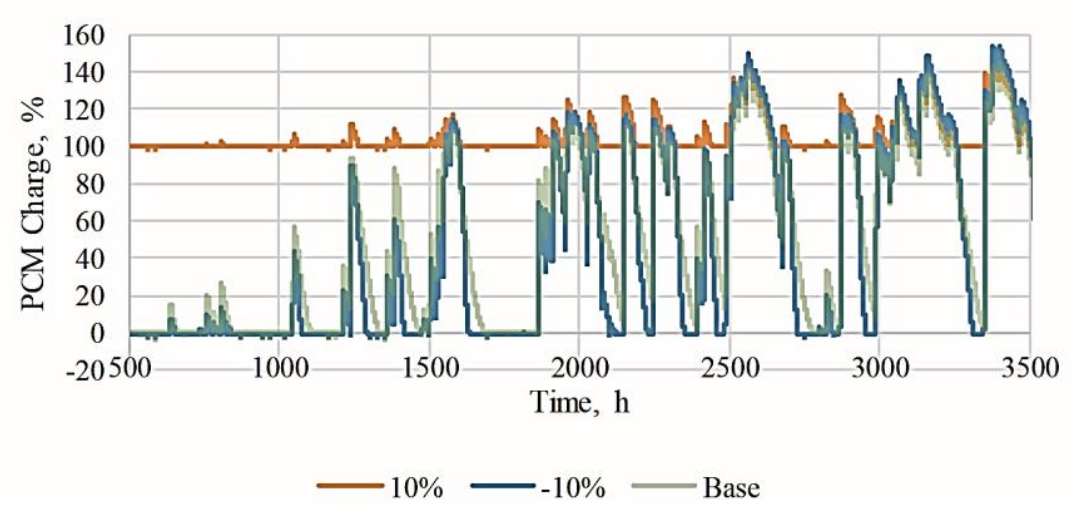

Fig. 9. Minute data for part of the year of PCM charge data for the base case and cases with increased and decreased by $10 \%$ heater setpoint.

\subsection{Coefficient of Variation}

The coefficient of variation for variances of melting point and heater setpoint in Fig. 10 have $R^{2}$ above 0.9 showing that for the cases with increase SF the coefficient of variation can be used as an indicator of the performance of the PCM. This suggests that $C V$ of PCM energy can be used to separate other possible impacts on increased SF which are not connected with PCM.

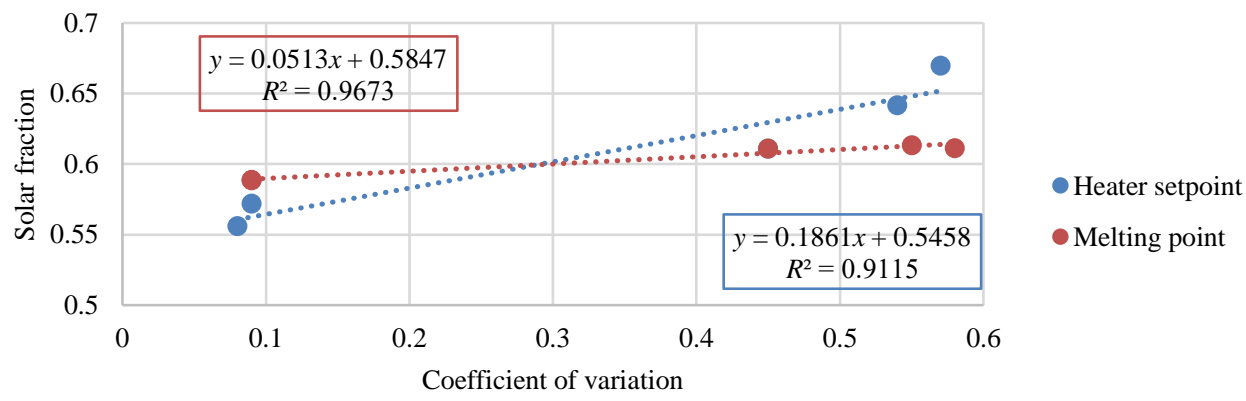

Fig. 10. Solar fraction correlation with the change of CV of energy in PCM for variances of melting point and heater setpoint.

In summary, this shows that primary solar thermal system performance parameters such as solar collector efficiency and solar fraction should be used, however, to analyse the role of PCM and how well PCM performs multiple parameters need to be looked at - ideally PCM charge graph such as in Fig. 7 should be analysed, however that requires at least a temperature in PCM to be measured.

\subsection{Latent Heat}

Increasing latent heat by $10 \%$ increase SF by $0.23 \%$ rel., while reduction by $10 \%$ reduces SF by $0.25 \%$ rel. The change in SF related to the latent heat change is linear with $R^{2}$ of 0.99 . With the assumption that linearity is kept outside the simulated range, it can be calculated that to increase 
solar fraction by $1 \%$ rel. it would require latent heat increase by $41 \%$, or in absolute values from $185 \mathrm{~kJ} / \mathrm{kg}$ to $261 \mathrm{~kJ} / \mathrm{kg}$.

\subsection{Thermal Conductivity}

Thermal conductivity change has an even smaller impact in the simulations, where it would have to be increased by $1000 \%$ to increase SF by $1 \%$ rel. This suggests that the high $\lambda_{\text {PCM }}$ used in the simulations $(4.5 \mathrm{~W} /(\mathrm{m} \cdot \mathrm{K}))$ is already high enough that further increase has little impact on SF.

\subsection{Number of Containers}

To increase SF by $1 \%$ rel. it would require increasing the number of containers by $58 \%$. However, that would not be realistically possible with a limited size of tank. The tank used in the simulation uses 150 containers, while theoretical maximum placement based on geometry is 171 , which allows a maximum of $14 \%$ increase in the number of containers or maximum SF increase by $0.23 \%$ rel.

\section{CONCLusion}

Sensitivity analysis using the OAT method shows that the main aspects that affect a solar fraction of the domestic solar hot water system are the melting point of the PCM and auxiliary heater setpoint temperature. If the melting point is $10 \%$ below required hot water temperature then PCM most of the year is in fully melted state and works as a sensible heat storage medium with inferior thermal properties compared to water, reducing SF by $3.2 \%$ rel. The melting point increase of $5 \%\left(57.8{ }^{\circ} \mathrm{C}\right)$ above hot water setpoint temperature provides the optimal increase in SF and collector efficiency from the variances analysed. $10 \%$ higher melting point has little impact $<1 \%$ rel. on SF.

Lower heater setpoint reduces storage temperature which reduces heat losses by up to $7.3 \%$ and reduces average yearly inlet temperature of the collector from $48.5^{\circ} \mathrm{C}$ to $47.6^{\circ} \mathrm{C}$ which results in solar collector efficiency increase by $0.6 \%$. However, due to reduced setpoint, the DHW temperature falls below $54{ }^{\circ} \mathrm{C}$ more than $50 \%$ of the supply period for a year. Increasing setpoint by $5 \%$ and $10 \%$ reduces SF by $4 \%$ and $5.5 \%$ respectively. Thermal conductivity and number of containers have a linear impact in the range analysed, and with a maximum change of $10 \%$ both affect solar fraction by less than $0.2 \%$ rel.

To analyse the processes in PCM a temperature measurement is required within the PCM to evaluate the fluctuations. Temperature values then allow to calculate and use parameters such as charge, average charge and coefficient of variation to better describe PCM utilization. $\mathrm{CV}$ based on energy in PCM has shown to have a good correlation with the change in SF with $R^{2}$ above 0.9 , however, it should be used in combination with temperature in PCM graphs to ensure that the variations happen around the melting point.

\section{ACKNOWLEDGEMENT}

This research is funded by the Ministry of Economics of the Republic of Latvia, project “Assessment of Latvia's renewable energy supply-demand economic potential and policy recommendations”, project No. VPP-EM-AER-2018/1-0001. 


\section{REFERENCES}

[1] Eurostat. Energy consumption in households - Statistics Explained. 2018 [Online]. [Accessed 05.02.2019]. Available: https://ec.europa.eu/eurostat/statisticsexplained/index.php/Energy_consumption_in_households\#cite_note-1

[2] Eurostat. Energy, transport and environment statistics 2019 edition. Luxembourg: Publications Office of the European Union, 2019.

[3] Eurostat. Supply, transformation and consumption of renewables and wastes [Online]. [Accessed 07.01.2020]. Available: https://appsso.eurostat.ec.europa.eu/nui/show.do?dataset=nrg_cb_rw\&lang=en

[4] Pakere I., Blumberga D. Solar Energy in Low Temperature District Heating. Environmental and Climate Technologies 2019:23(3):147-158. https://doi.org/10.2478/rtuect-2019-0085

[5] Weiss W., Biermayr P. Potential of Solar Thermal in Europe. Brussels: ESTIF, 2008.

[6] Hansen K., Vad Mathiesen B. Comprehensive assessment of the role and potential for solar thermal in future energy systems. Solar Energy 2018:169:144-152. https://doi.org/10.1016/j.solener.2018.04.039

[7] Zalba B., et al. Review on thermal energy storage with phase change: materials, heat transfer analysis and applications. Applied Thermal Engineering 2003:23(3):251-283. https://doi.org/10.1016/S1359-4311(02)00192-8

[8] Salunkhe P. B., Shembekar P. S. A review on effect of phase change material encapsulation on the thermal performance of a system. Renewable and Sustainable Energy Reviews 2012:16(8):5603-5616. https://doi.org/10.1016/j.rser.2012.05.037

[9] Reddy K. S., Mudgal V., Mallick T. K. Review of latent heat thermal energy storage for improved material stability and effective load management. Journal of Energy Storage 2018:15:205-227. https://doi.org/10.1016/j.est.2017.11.005

[10] Humphries W. R., Marshall G. C. Performance of finned thermal capacitators. Washington: NASA, 1974.

[11] Farid M. M., Kanzawa A. Thermal performance of a heat storage module using pcm's with different melting temperatures: Mathematical modeling. Journal of Solar Energy Engineering 1989:111(2):152-157. https://doi.org/10.1115/1.3268301

[12] Kousksou T., et al. PCM storage for solar DHW: From an unfulfilled promise to a real benefit. Solar Energy 2011:85(9):2033-2040. https://doi.org/10.1016/j.solener.2011.05.012

[13] Talmatsky E., Kribus A. PCM storage for solar DHW: An unfulfilled promise? Solar Energy 2008:82(10):861-869. https://doi.org/10.1016/j.solener.2008.04.003

[14] Bhagat K., Prabhakar M., Saha S. K. Estimation of thermal performance and design optimization of finned multitube latent heat thermal energy storage. Journal of Energy Storage 2018:19:135-144. https://doi.org/10.1016/j.est.2018.06.014

[15] Kenjo L., Inard C., Caccavelli D. Experimental and numerical study of thermal stratification in a mantle tank of a solar domestic hot water system. Applied Thermal Engineering 2007:27(11-12):1986-1995. https://doi.org/10.1016/j.applthermaleng.2006.12.008

[16] Liu M., Saman W., Bruno F. Validation of a mathematical model for encapsulated phase change material flat slabs for cooling applications. Applied Thermal Engineering 2011:31(14-15):2340-2347. https://doi.org/10.1016/j.applthermaleng.2011.03.034

[17] Bonk S. Methodology for the Assessment of the Hot Water Comfort of Factory Made Systems and Custom Built Systems. Stuttgart: University of Stuttgart (ITW), 2012.

[18] Cabinet of Ministers. Noteikumi par Latvijas būvnormatīvu LBN 221-15. (Regulations for Latvian building norm LBN 221-15.) Ministry of Economics, 2015. (in Latvian)

[19] Dzikevics M., Ansone A., Veidenbergs I. Experimental investigation of flow rate impact on thermal accumulation system with PCM. Energy Procedia 2017:128:386-392. https://doi.org/10.1016/j.egypro.2017.09.043

[20] Streicher W., et al. Simulation models of PCM storage units. A report of IEA Solar Heating and Cooling Programme. Task 32: Advanced Storage Concepts for Solar and Low Energy Buildings. Report C5. Graz: Graz University of Technology, 2008.

[21] Schranzhofer H., et al. Validation of a TRNSYS simulation model for PCM energy storage and PCM wall construction elements. Graz: Graz University of Technology, 2006. 

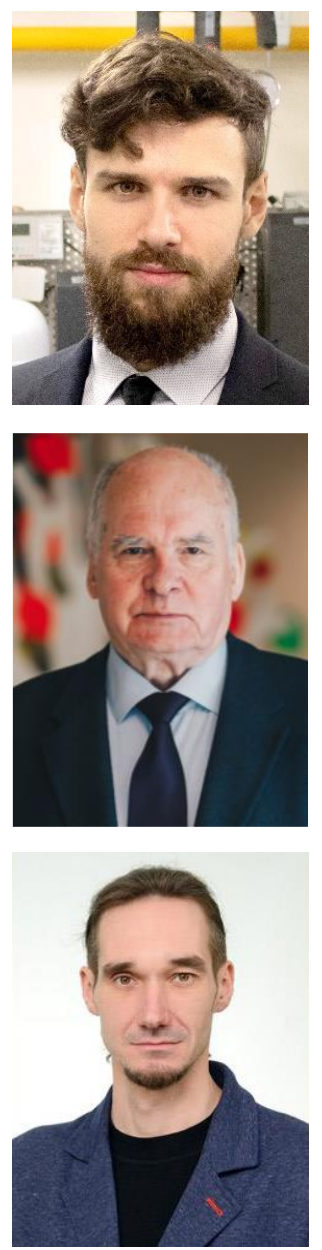

Mikelis Dzikevics received the Ph.D. degree from Riga Technical University, Institute of Energy Systems and Environment in 2019. The major fields of study are solar and biomass thermal energy systems and energy storage.

Mikelis Dzikevics is holding a researcher position within Riga Technical University since 2014. He is actively participating in national and international research projects and is author of 14 publications. Some of the topics are regarding experimental and mathematical simulation of solar thermal storage using phase change materials and research of flue-gas treatment.

E-mail: Mikelis.Dzikevics@rtu.lv

ORCID iD: https://orcid.org/0000-0001-9467-2569

Ivars Veidenbergs, Dr. habil. sc. ing. professor has been a part of academic staff of the Institute of Energy Systems and Environment, Faculty of Electrical and Environmental Engineering, Riga Technical University. He has thermal engineering diploma (1960) in speciality "Thermal equipment of thermal power stations" and two steps doctoral degree diploma. Ph. D. thesis "Dynamic Temperature Regimes of Thermoelectric Cooling Devices" was defended in Riga Polytechnic Institute (1975). Doctor Habilitus thesis "Engineering Methods for Calculating Heat and Mass Transfer in the devices of Power Units" was defended in Faculty of Electrical and Environmental Engineering, Riga Technical University (1992). The main research area is energy and environment. He is an author of more than 180 publications and 5 books.

E-mail: Ivars.Veidenbergs@ rtu.lv

Kęstutis Valančius received the Ph.D. degree from Vilnius Gediminas Technical University in 2007. The major fields of study are thermal modelling of buildings, building microclimate and building energy systems.

He is holding an associate professor position within Vilnius Gediminas Technical University, Department of Building Energetics since 2007. He is an author of 21 publications. Some of the topics are solar energy use for renovating of buildings and experimental analysis of PCMbased copper heat exchanger.

E-mail: kestutis.valancius@vgtu.lt 